\title{
Washington University School of Medicine Digital Commons@Becker
}

Open Access Publications

$10-2012$

\section{The use of live attenuated influenza vaccine (LAIV) in healthcare personnel (HCP): Guidance from the society for healthcare epidemiology of America (SHEA)}

Thomas R. Talbot

Vanderbilt University School of Medicine

Hilary Babcock

Washington University School of Medicine in St. Louis

Deborah Cotton

Boston University School of Medicine

Lisa L. Maragakis

Johns Hopkins University School of Medicine

Gregory A. Poland

Mayo Clinic College of Medicine

See next page for additional authors

Follow this and additional works at: https://digitalcommons.wustl.edu/open_access_pubs

Part of the Medicine and Health Sciences Commons

\section{Recommended Citation}

Talbot, Thomas R.; Babcock, Hilary; Cotton, Deborah; Maragakis, Lisa L.; Poland, Gregory A.; Septimus, Edward J.; Tapper, Michael L.; and Weber, David J., ,"The use of live attenuated influenza vaccine (LAIV) in healthcare personnel (HCP): Guidance from the society for healthcare epidemiology of America (SHEA)." Infection Control and Hospital Epidemiology.33,10. 981-983. (2012). https://digitalcommons.wustl.edu/open_access_pubs/1201 


\section{Authors}

Thomas R. Talbot, Hilary Babcock, Deborah Cotton, Lisa L. Maragakis, Gregory A. Poland, Edward J.

Septimus, Michael L. Tapper, and David J. Weber 


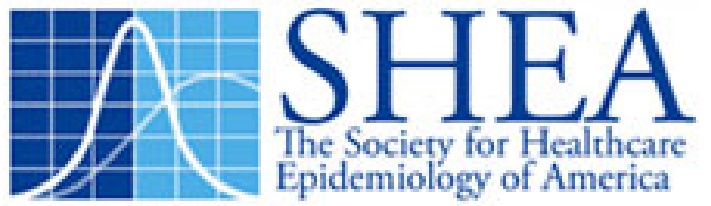

The Use of Live Attenuated Influenza Vaccine (LAIV) in Healthcare Personnel (HCP): Guidance from the Society for Healthcare Epidemiology of America (SHEA)

Author(s): Thomas R. Talbot, MD, MPH; Hilary Babcock, MD, MPH; Deborah Cotton, MD, MPH; Lisa L. Maragakis, MD, MPH; Gregory A. Poland, MD; Edward J. Septimus, MD; Michael L. Tapper, MD; David J. Weber, MD, MPH, writing as the SHEA Task Force on Healthcare Personnel Influenza Vaccination

Reviewed work(s):

Source: Infection Control and Hospital Epidemiology, Vol. 33, No. 10 (October 2012), pp. 981983

Published by: The University of Chicago Press on behalf of The Society for Healthcare Epidemiology of America

Stable URL: http://www.jstor.org/stable/10.1086/667772

Accessed: $0 7 \longdiv { / 1 0 / 2 0 1 2 ~ 1 7 : 3 4 }$

Your use of the JSTOR archive indicates your acceptance of the Terms \& Conditions of Use, available at http://www.jstor.org/page/info/about/policies/terms.jsp

JSTOR is a not-for-profit service that helps scholars, researchers, and students discover, use, and build upon a wide range of content in a trusted digital archive. We use information technology and tools to increase productivity and facilitate new forms of scholarship. For more information about JSTOR, please contact support@jstor.org. 


\title{
The Use of Live Attenuated Influenza Vaccine (LAIV) in Healthcare Personnel (HCP): Guidance from the Society for Healthcare Epidemiology of America (SHEA)
}

\author{
Thomas R. Talbot, MD, MPH; ${ }^{1}$ Hilary Babcock, MD, MPH $;^{2}$ Deborah Cotton, MD, MPH; ${ }^{3,4}$ \\ Lisa L. Maragakis, MD, MPH $;{ }^{5}$ Gregory A. Poland, MD; ${ }^{6}$ Edward J. Septimus, MD; ${ }^{78}$ Michael L. Tapper, MD; ${ }^{9}$ \\ David J. Weber, MD, MPH, ${ }^{10}$ writing as the SHEA Task Force on Healthcare Personnel Influenza Vaccination
}

\begin{abstract}
Because of the live viral backbone of live attenuated influenza vaccine (LAIV), questions have arisen regarding infection control precautions and restrictions surrounding its use in healthcare personnel (HCP). This document provides guidance from the Society for Healthcare Epidemiology of America regarding use of LAIV in HCP and the infection control precautions that are recommended with its use in this population.
\end{abstract}

Infect Control Hosp Epidemiol 2012;33(10):981-983

Vaccination of healthcare personnel (HCP) against influenza is a key component of efforts to protect patients and other HCP from healthcare-associated influenza transmission. HCP influenza vaccination rates are slowly increasing, reaching $63.5 \%$ for the 2010-2011 influenza season, ${ }^{1}$ but they remain well below the Healthy People 2020 Goal of $90 \%$. Fortunately, an increasing array of influenza vaccines are or will soon be available to optimize recipient immune response to the vaccine as well as allow for different modes of vaccine delivery. These options include various types of inactivated influenza vaccines, such as the standard seasonal trivalent inactivated vaccine (TIV), the high-dose TIV that produces an improved immune response in older adults, ${ }^{2}$ and the intradermal TIV, which uses a smaller needle and less viral antigen than the standard intramuscular TIV. ${ }^{3}$ A new inactivated quadrivalent vaccine is being developed that adds a second influenza $B$ strain in order to reduce the potential for vaccine mismatch when compared with circulating wild-type strains. ${ }^{4}$ Finally, a non-egg-based influenza vaccine grown in a cell line will likely be available in the United States in a few years. ${ }^{5}$

The other major type of licensed influenza vaccine is the live attenuated influenza vaccine (LAIV). Currently utilized LAIVs are trivalent, but a quadrivalent LAIV vaccine (that targets 2 strains of influenza A and 2 strains of influenza B) was recently approved by the US Food and Drug Administration, although it is not expected to be commercially available until the 2013-2014 influenza season. LAIV is an attenuated live viral vaccine with a temperature-sensitive adaptation that precludes replication of the virus at human core body temperatures. Administered intranasally, the vaccine replicates in the lower-temperature area of the nasal mucosa, allowing for the development of mucosal as well as systemic immunity. LAIV, which is licensed for healthy, nonpregnant persons aged 2-49 years, provides adults with another option for influenza vaccination, particularly for those with an aversion to needles. However, in a study of persons aged 18-49 years, although LAIV was efficacious in preventing laboratory-confirmed influenza, it was not as efficacious as TIV, a finding that differs from analysis of data obtained in children. ${ }^{6,7}$

On the basis of currently available data, TIV appears to be the preferred vaccine for adults, with LAIV as an acceptable alternative. Because of its live viral backbone, questions have arisen regarding infection control precautions and restrictions surrounding the use of LAIV in HCP. This document provides guidance regarding the use of LAIV in HCP and the infection control precautions that are recommended with its use in this population.

Affiliations: 1. Departments of Medicine and Preventive Medicine, Vanderbilt University School of Medicine, Nashville, Tennessee; 2. Department of Internal Medicine, Washington University School of Medicine, St. Louis, Missouri; 3. Department of Medicine, Boston University School of Medicine, Boston, Massachusetts; 4. Department of Epidemiology, Boston University School of Public Health, Boston, Massachusetts; 5. Department of Medicine, Johns Hopkins University School of Medicine, Baltimore, Maryland; 6. Department of Medicine, Mayo Clinic College of Medicine, Rochester, Minnesota; 7. Hospital Corporation of America, Nashville, Tennessee; 8. Texas A\&M Health Science Center, Bryan, Texas; 9. Lenox Hill Hospital and the New York University School of Medicine, New York, New York; 10. Departments of Medicine and Pediatrics, University of North Carolina, Chapel Hill, North Carolina.

Received July 17, 2012; accepted July 18, 2012; electronically published September 6, 2012.

(C) 2012 by The Society for Healthcare Epidemiology of America. All rights reserved. 0899-823X/2012/3310-0003\$15.00. DOI: 10.1086/667772 


\section{LAIV AND VIRAL SHEDDING}

Shedding of attenuated vaccine virus is common in the first few days following vaccination with LAIV; ${ }^{8,9}$ however, the quantity of attenuated virus shed in adults is 100-10,000-fold lower than the median human infectious dose required for LAIV vaccination in adults. ${ }^{8}$ Reversion of LAIV virus to wildtype virus has never been demonstrated despite extensive testing. ${ }^{10}$ Importantly, secondary transmission from a person who recently received the LAIV that resulted in clinically important illness has never been reported in the medical literature, ${ }^{11}$ and to date there has been only 1 documented episode of LAIV virus transmission, which occurred in a day care attendee as part of a placebo-controlled LAIV trial. ${ }^{12}$ The virus obtained from this subject retained LAIV attenuation, and virus could not be recovered in additional specimens collected from the subject. No additional cases of LAIV transmission have been reported to the manufacturer of the only licensed LAIV (C. Rizzo, MedImmune, personal communication, April 13, 2012).

\section{USE OF LAIV IN HCP}

On the basis of a theoretical concern for transmission and despite the absence of evidence of an increased risk of secondary transmission of infection by LAIV recipients, the Centers for Disease Control and Prevention's Advisory Committee on Immunization Practices and Healthcare Infection Control Practices Advisory Committee have recommended that LAIV not be administered to HCP who interact with patients who at the time of contact require a protective environment (defined as a "specialized patient-care area with a positive airflow relative to the corridor, high-efficiency particulate air filtration, and frequent air changes," as found in myelosuppression or stem cell transplantation units). ${ }^{13,14}$ This recommendation was made as a result of an abundance of caution and a desire to err on the side of patient safety. Updated guidelines from 2010 even note that "some healthcare facilities might choose to not restrict use of LAIV in close contacts of severely immunocompromised persons, based on the lack of evidence for transmission in health-care settings since licensure in 2004." ${ }^{14}$

Studies have noted the safety of administering LAIV to some populations of immunocompromised patients of concern, including HIV-positive children ${ }^{15}$ and adults, ${ }^{16}$ older adults with chronic obstructive pulmonary disease, ${ }^{17}$ children with cancer, ${ }^{18}$ and adults aged 65 years and older who have chronic medical conditions, ${ }^{19}$ although none of these studies included subjects considered to be markedly immunocompromised. During the influenza A/California/7/2009 (H1N1) pandemic, the first wave of available vaccine consisted of LAIV and many of the initial doses of LAIV were earmarked for HCP. Some HCP expressed concern regarding the use of a "live" vaccine in persons that might have close contact with immunosuppressed patients, highlighting continued confusion and uncertainty regarding the use of LAIV among $\mathrm{HCP}^{20}$
Admittedly, because most healthcare facilities have avoided the use of LAIV in HCP, there continues to be limited experience with and data on the use of LAIV in healthcare settings.

\section{SOCIETY FOR HEALTHCARE EPIDEMIOLOGY OF AMERICA (SHEA) GUIDANCE ON THE USE OF LAIV IN HCP}

SHEA endorses the use of LAIV as an alternative to the inactivated influenza vaccine, particularly for those HCP who avoid an annual influenza vaccination because of fear of needle injections. SHEA also agrees with the restriction of LAIV from those HCP who, in the week following vaccination, have frequent contact with patients who reside in a protective environment (eg, HCP in a bone marrow transplantation unit), but it notes that this recommendation is made as a result of an abundance of caution. Those HCP who have frequent contact with patients in protective environments but who will not care for such patients in the week following vaccination may still receive LAIV. HCP who have the potential for infrequent contact with patients in protective environments (ie, when the majority of patients contacted do not reside in a protective environment, such as a radiology technologist performing a chest radiograph or an emergency department physician during the initial patient evaluation) should not be excluded from vaccination with LAIV. Finally, HCP who provide care to other immunosuppressed populations (eg, neonatal and burn unit patients and oncologic patients undergoing chemotherapy but not requiring a formal protective environment) may still receive LAIV.

\section{ACKNOWLEDGMENTS}

Potential conflicts of interest. T.R.T. reports that he has served as an advisor to Joint Commission Resources; he has received honoraria from QuantiaMD; and his spouse has received research support from Wyeth, Vaxxinate, and Sanofi Pasteur. H.B. reports that she has received honoraria from Sanofi Pasteur. G.A.P. reports that he has served as an advisor or consultant to Merck, Avianax, Liquidia Technologies, Novartis Vaccines, PAXVAX, CSL Biotherapies, and Sanofi Pasteur. M.L.T. reports that he served as an advisor or consultant to Genentech and Pfizer and has received honoraria from Gilead Sciences. D.J.W. has served as an advisor or consultant to Merck and Pfizer and has received honoraria from Pfizer, Merck, and Sanofi Pasteur. L.L.M., D.C., and E.J.S. report no conflicts of interest relevant to this article. All authors submitted the ICMJE Form for Disclosure of Potential Conflicts of Interest, and the conflicts that the editors consider relevant to this article are disclosed here.

Address correspondence to Thomas R. Talbot, MD, MPH, A-2200 Medical Center North 1161 21st Avenue South, Vanderbilt University Medical Center, Nashville, TN 37232 (tom.talbot@vanderbilt.edu).

This article was approved by the Board of the Society for Healthcare Epidemiology of America.

\section{REFERENCES}

1. Centers for Disease Control and Prevention. Influenza vacci- 
nation coverage among health-care personnel: United States, 2010-11 influenza season. MMWR Morb Mortal Wkly Rep 2011; 60(32):1073-1077.

2. Centers for Disease Control and Prevention. Licensure of a highdose inactivated influenza vaccine for persons aged $\geq 65$ years (Fluzone High-Dose) and guidance for use: United States, 2010. MMWR Morb Mortal Wkly Rep 2010;59(16):485-486.

3. Fluzone Intradermal (influenza virus vaccine): facts at a glance. http://multivu.prnewswire.com/mnr/sanofipasteur/49833/docs /49833-Fluzone_ID_Fact_Sheet.pdf. Accessed May 22, 2012.

4. Greenberg DP, Robertson C, Talbot HK, Decker MD. Safety and immunogenicity of a quadrivalent inactivated influenza vaccine (QIV) containing two A and two B strains among persons $\geq 65$ years of age. Paper presented at: 49th Annual Meeting of the Infectious Diseases Society of America, 21 October 2011; Boston, MA. https://idsa.confex.com/idsa/2011/webprogram/Paper31024 .html. Accessed May 22, 2012.

$\rightarrow$ 5. Gregersen JP, Schmitt HJ, Trusheim H, Broker M. Safety of MDCK cell culture-based influenza vaccines. Future Microbiol 2011;6(2):143-152.

$\rightarrow$ 6. Monto AS, Ohmit SE, Petrie JG, et al. Comparative efficacy of inactivated and live attenuated influenza vaccines. $N$ Engl J Med 2009;361(13):1260-1267.

$\rightarrow$ 7. Belshe RB, Edwards KM, Vesikari T, et al. Live attenuated versus inactivated influenza vaccine in infants and young children. $N$ Engl J Med 2007;356(7):685-696.

$\rightarrow$ 8. Block SL, Yogev R, Hayden FG, Ambrose CS, Zeng W, Walker RE. Shedding and immunogenicity of live attenuated influenza vaccine virus in subjects 5-49 years of age. Vaccine 2008;26(38): 4940-4946.

$\rightarrow$ 9. Hammitt LL, Bartlett JP, Li S, et al. Kinetics of viral shedding and immune responses in adults following administration of cold-adapted influenza vaccine. Vaccine 2009;27(52):7359-7366.

$\rightarrow$ 10. Tosh PK, Boyce TG, Poland GA. Flu myths: dispelling the myths associated with live attenuated influenza vaccine. Mayo Clin Proc 2008;83(1):77-84.

$\rightarrow$ 11. Fiore AE, Shay DK, Broder K, et al. Prevention and control of seasonal influenza with vaccines: recommendations of the Advisory Committee on Immunization Practices (ACIP), 2009. MMWR Recomm Rep 2009;58(RR-8):1-52.
12. Vesikari T, Fleming DM, Aristegui JF, et al. Safety, efficacy, and effectiveness of cold-adapted influenza vaccine-trivalent against community-acquired, culture-confirmed influenza in young children attending day care. Pediatrics 2006;118(6):2298-2312.

13. Pearson ML, Bridges CB, Harper SA. Influenza vaccination of health-care personnel: recommendations of the Healthcare Infection Control Practices Advisory Committee (HICPAC) and the Advisory Committee on Immunization Practices (ACIP). MMWR Recomm Rep 2006;55(RR-2):1-16.

14. Centers for Disease Control and Prevention. Additional information about vaccination of specific populations: persons who live with or care for persons at higher risk for influenzarelated complications. http://www.cdc.gov/flu/professionals/acip /specificpopulations.htm. Accessed August 24, 2012.

15. Levin MJ, Song LY, Fenton T, et al. Shedding of live vaccine virus, comparative safety, and influenza-specific antibody responses after administration of live attenuated and inactivated trivalent influenza vaccines to HIV-infected children. Vaccine 2008;26(33):4210-4217.

16. King JC Jr, Treanor J, Fast PE, et al. Comparison of the safety, vaccine virus shedding, and immunogenicity of influenza virus vaccine, trivalent, types $\mathrm{A}$ and $\mathrm{B}$, live cold-adapted, administered to human immunodeficiency virus (HIV)-infected and nonHIV-infected adults. J Infect Dis 2000;181(2):725-728.

17. Gorse GJ, O'Connor TZ, Young SL, et al. Efficacy trial of live, cold-adapted and inactivated influenza virus vaccines in older adults with chronic obstructive pulmonary disease: a VA cooperative study. Vaccine 2003;21(17-18):2133-2144.

18. Carr S, Allison KJ, Van De Velde LA, et al. Safety and immunogenicity of live attenuated and inactivated influenza vaccines in children with cancer. J Infect Dis 204(10):1475-1482.

19. Jackson LA, Holmes SJ, Mendelman PM, Huggins L, Cho I, Rhorer J. Safety of a trivalent live attenuated intranasal influenza vaccine, FluMist, administered in addition to parenteral trivalent inactivated influenza vaccine to seniors with chronic medical conditions. Vaccine 1999;17(15-16):1905-1909.

20. Hernandez L. Hospitals shun H1N1 FluMist vaccine, wait for injections. October 6, 2009. http://www.thedenverchannel.com /news/21212055/detail.html. Accessed June 6, 2012. 